\title{
Use of Royal Darwin Hospital emergency department by immigration detainees in 2011
}

\begin{abstract}
Adrienne K Deans MB BS, FRACGP, FACEM Emergency Physician

Clare J Boerma MB BS

Intern

James Fordyce MB BS, MPH, FACEM Emergency Physician

Mark De Souza

MB BS, FACEM Emergency Physician

Didier J Palme FRCP, FRCS, FACEM, Director of Emergency Medicine

Joshua S Davis MB BS, FRACP, PhD Senior Research Fellow

1 Royal Darwin Hospital, Darwin, NT.

2 Global and Tropical Health Division, Menzies School of Health Research, Darwin, NT.

joshua.davis@ menzies.edu.au
\end{abstract}

MJA 2013; 199: 776-778 doi: 10.5694/mial3.10447

Editorial $p 72$ Perspective $p 730$ everal thousand people arrive in Australia without a visa each year and seek asylum by applying for recognition as refugees. While awaiting processing, these asylum seekers are involuntarily detained by the Australian Government for periods ranging from 1-2 months to several years, and, in 2011, the majority of detainees had been in detention for at least 6 months. ${ }^{1}$ Previous studies have shown a high burden of physical and psychiatric morbidity - especially mental health problems, self-harm and suicide attempts - in asylum seekers, particularly those held in immigration detention. ${ }^{2-5}$

Darwin, in the Northern Territory, receives a substantial proportion of the asylum seekers who arrive in Australia and on Christmas Island by boat, and had two major immigration detention facilities in 2011. The first, the Northern Immigration Detention Centre, is a high-security detention centre that houses men, and has a capacity of 456 people. The second, Darwin Airport Lodge, houses families and unaccompanied minors, and has a capacity of 435 people. A third major facility opened in Darwin at Wickham Point in December 2011, and has a capacity of 1500 people. In a 2010 report, the Australian Human Rights Commission raised serious concerns about the provision of health services to immigration detainees in Darwin. ${ }^{6}$ In a 2013 AuditorGeneral report, it was shown that about $40 \%$ of surveyed immigration detainees in Australia said that their basic health care needs had not been met. $^{7}$

Despite large numbers of immigration detainees in Darwin, only one public hospital serves their needs - the Royal Darwin Hospital (RDH), a 350-bed teaching hospital with an emergency department (ED) that sees about 65000 patients per year. We noticed a large burden of morbidity, particularly self-harm, in asylum seekers attending the RDH ED in 2010 and 2011. Since no data quanti-

Abstract

Objective: To describe the number and nature of emergency department (ED) attendances by immigration detainees in Darwin, in the Northern Territory, over a 12-month period.

Design and setting: Retrospective observational study of immigration detainees attending the Royal Darwin Hospital ED during the 2011 calendar year.

Main outcome measures: Number of ED attendances and primary diagnoses.

Results: In 2011, there were 770 ED attendances by 518 individual detainees at Royal Darwin Hospital. Those who attended the ED had a mean (SD) age of 27.6 (12.2) years, and 112 of them (21.6\%) were children. Most (413, 79.7\%) were male, and Iran and Afghanistan were the two most common countries of birth. We estimate that $50.1 \%(95 \% \mathrm{Cl}, 47.0 \%-53.2 \%)$ of immigration detainees in Darwin (mean, 776 per month; total, 1034), attended the Royal Darwin Hospital ED at least once in 2011. The most common primary diagnosis was psychiatric problems (187 attendances, 24.3\%), including self-harm (138 attendances, $17.9 \%)$.

Conclusion: In 2011, asylum seekers in immigration detention in Darwin had a high prevalence of unmet health needs and substantial levels of psychiatric morbidity. The primary health care provided to them was inadequate.

fying this burden were publicly available, we undertook a retrospective audit of RDH ED attendances by immigration detainees during 2011.

\section{Methods}

We retrospectively audited RDH ED attendances during the 2011 calendar year for people identified, using the hospital's financial coding, as immigration detainees. The number of detainees attending, demographic information, and time and date of attendances were extracted from the hospital's data warehouse. Clinical information was manually extracted by reviewing the ED clinical database, a custom-built database for prospectively recording details of each episode of care. Broad categorical primary and secondary diagnoses were those recorded by the ED doctor at the time of presentation. The primary diagnosis was defined as the primary reason for attending the ED. The secondary diagnosis, if any, was defined as a coexisting active medical problem that contributed to the ED attendance.

Data were entered into a purposebuilt Microsoft Access database and analysed using Stata version 10 (Statacorp). As we did not have access to accurate data on the number of people in immigration detention in Darwin during 2011, we estimated the denominators using data summaries on the number of people in immigration detention that are released every 1-2 months by the Department of Immigration and Citizenship. ${ }^{1}$ These reports provide detainee numbers for immigration detention centres (IDCs) (eg, the Northern Immigration Detention Centre), but only provide nationallevel summary data for facilities classified as alternative places of detention (APODs) (eg, Darwin Airport Lodge). We assumed that the proportion of total Australian mainland detainees resident in APODs in Darwin was the same as the proportion of total Australian mainland detainees resident in IDCs in Darwin. Hence we estimated the number of immigration detainees in Darwin in each month of 2011 for which data were available as: $\mathrm{NIDC}+(\mathrm{NIDC} \div \mathrm{MIDC} \times \mathrm{MAPOD})$. In this calculation, NIDC is the number of detainees in the Northern Immigration Detention Centre, MIDC is the number of detainees in all mainland IDCs combined, and MAPOD is the number of detainees in all mainland APODs combined. The mean of these monthly numbers was calculated as an estimate of the 
average number of detainees resident in Darwin during 2011.

The study was approved by the Human Research Ethics Committee of the Menzies School of Health Research and Northern Territory Department of Health and Families.

\section{Results}

In 2011, there were 770 ED attendances at RDH by 518 individual detainees; the mean (SD) age of these detainees was 27.6 (12.2) years, 112 $(21.6 \%)$ of them were aged $<18$ years, and $413(79.7 \%)$ were male. Iran and Afghanistan were the two most common countries of birth (283 and 90 individuals, respectively), followed by Iraq (63), Indonesia (24), Sri Lanka (14), and other countries (44).

We estimated that there was a mean of 776 individuals living in immigration detention in Darwin during 2011 (monthly range, 561-920 individuals) (Box 1). If we assume there was no population turnover during this time, this would mean that $518 \div 776=66.8 \% \quad(95 \% \quad$ CI, $63.3 \%-$ $70.1 \%)$ of these people attended the ED at least once in 2011. If we assume the entire population was replaced every month, then the proportion who attended the ED at least once would be $66.8 \% \times 1 / 12=5.6 \%$. Given that the median length of stay by asylum seekers in immigration detention in 2011 was about 9 months, ${ }^{1}$ we estimate that $66.8 \% \times 9 / 12=50.1 \%$ (95\% CI, $47.0 \%-53.2 \%$ ) of immigration detainees in Darwin attended the RDH ED at least once in 2011. The mean monthly ED attendance rate for detainees was 1.06 attendances per person-year and, based on 9-month length of stay, we estimate that 1035 people passed through Darwin's immigration detention facilities in 2011.

\section{Detainees' clinical characteristics}

Each patient who presents to the ED has the urgency of his or her condition assessed and is assigned a triage category, from category 1 (needs immediate resuscitation) to category 5 (non-urgent problem). In 2011, the pattern of triage categories for immigration detainees was similar to that for all patients, but hospital admission

1 Estimated immigration detainee population and numbers and rates of ED attendance by month, Darwin, 2011

\begin{tabular}{|c|c|c|c|c|c|c|c|c|c|c|c|c|c|c|}
\hline & Jan & Feb & Mar & Apr & May & Jun & Jul & Aug & Sep & Oct & Nov & Dec & Mean & Total \\
\hline Estimated population & 873 & 912 & 890 & 920 & 853 & nd & 695 & nd & 666 & 561 & 616 & nd & 776 & $1035 *$ \\
\hline Number of ED attendances & 88 & 76 & 72 & 70 & 61 & 51 & 47 & 50 & 65 & 65 & 63 & 62 & - & 770 \\
\hline $\begin{array}{l}\text { Number of individuals who } \\
\text { attended ED at least once }\end{array}$ & 64 & 48 & 51 & 47 & 46 & 31 & 25 & 36 & 45 & 43 & 38 & 44 & - & $518^{\dagger}$ \\
\hline ED attendance rate & 1.21 & 1.00 & 0.97 & 0.91 & 0.86 & nd & 0.81 & nd & 1.17 & 1.39 & 1.23 & nd & 1.06 & - \\
\hline
\end{tabular}

$\mathrm{ED}=$ emergency department. $\mathrm{nd}=$ not determined (insufficient data). * Estimated total number of people who passed through Darwin's immigration detention facilities in 2011 , based on 9-month median length of stay. $†$ Total number of unique individuals (ie, individuals were not counted more than once if they attended the ED more than once in the same or subsequent months). $\ddagger$ Attendances per person-year (number of ED attendances $\div$ estimated population $\times 12$ ).

rates were substantially lower for immigration detainees in all triage categories except category 5, and the differences were significant for categories 2, 3 and 4 (Box 2).

The most common primary reason for attendance was a psychiatric problem; it accounted for 187 (24.3\%) of primary diagnoses, of which 138 were for self-harm (Box 3) (15 of these attendances were by children, who were aged 9-17 years). These incidents ranged from minor injuries (eg, superficial cuts and burns) to life-threatening injuries (eg, attempted hanging, lacerated arteries and intentional medication overdose). Including primary and secondary diagnoses, psychiatric problems were diagnosed for 223 attendances (29.0\%). The proportion of patients admitted to hospital who were diagnosed with a psychiatric problem was not related to country of birth, but males were more likely to attend for self-harm than females (141/ 624 [22.6\%] v 3/146 [2.1\%]; odds ratio, 13.9 [95\% CI, 4.4-44.3]).

Infection-related presentations were uncommon. Most presentations were for chronic or non-specific conditions, including musculoskeletal conditions (back pain, myalgia or arthralgia), gastrointestinal conditions (non-specific abdominal pain or diarrhoea), respiratory problems (asthma exacerbations), neurological problems (headaches) and non-cardiac chest pain.

Of 146 ED attendances by children, the most common primary diagnoses were musculoskeletal problems (53, $36.3 \%)$, respiratory problems (17, $11.6 \%$ ) and infectious diseases (14, 9.6\%). Psychiatric presentations were less common in children $(20,13.7 \%)$ than in adults $(203,32.5 \%)(P<0.001)$.

Of the 518 individuals who attended the ED, 155 attended twice or more during 2011, and 56 attended three or more times. One detainee attended 16 times for asthma. Of the 770 attendances, 309 (40.1\%) involved one or more pathology tests, 246 (31.9\%) involved plain radiography, 39 (5.1\%) involved a computed tomography or magnetic resonance imaging scan, and $23(3.0 \%)$ involved ultrasound. In 162 attendances $(21.0 \%)$, the patient was referred to one or more inpatient teams for assessment. In 99 attendances $(12.9 \%)$, the patient required admission to the ED or hospital wards.

\section{Discussion}

Although it has been clear for years that there is a large burden of physical and mental illness in immigration detainees, our finding that more than half of immigration detainees in Darwin attended the RHD ED over a 12month period suggests this problem is worse than previously suspected. This is likely to reflect two main contributing factors: a high burden of morbidity and poor access to primary health care services at detention facilities.

2 Hospital admission rates according to triage category for
immigration detainees and all patients who attended the
Royal Darwin Hospital emergency department in 2011


3 Primary and secondary diagnoses for 770 Royal Darwin Hospital emergency department attendances by immigration detainees in 2011

\begin{tabular}{lcc} 
& $\begin{array}{c}\text { Primary } \\
\text { diagnosis } \\
(n=770)\end{array}$ & $\begin{array}{c}\text { Secondary } \\
\text { diagnosis } \\
(n=113)\end{array}$ \\
\hline Psychiatric problem, including self-harm & $187(24.3 \%)$ & 46 \\
Self-harm & $138(17.9 \%)$ & 6 \\
Musculoskeletal condition & $178(23.1 \%)$ & 33 \\
Gastrointestinal or genitourinary & $117(15.2 \%)$ & 8 \\
condition & $70(9.1 \%)$ & 5 \\
Respiratory problem & $59(7.7 \%)$ & 5 \\
Neurological problem & $57(7.4 \%)$ & 4 \\
Cardiovascular problem & $33(4.3 \%)$ & 2 \\
Infectious disease & $16(2.1 \%)$ & 0 \\
Obstetric or gynaecological problem & $10(1.3 \%)$ & 0 \\
Dental problem & $8(1.0 \%)$ & 0 \\
Eye problem & $35(4.5 \%)$ & 10 \\
Other & &
\end{tabular}

A high burden of morbidity has previously been described in asylum seekers and immigration detainees in Australia ${ }^{3,5}$ and overseas. ${ }^{2,4,8-10}$ The primary health care services at Australian immigration detention facilities were described as understaffed and inadequate in a 2010 Australian Human Rights Commission report. ${ }^{6}$ Our 2011 data support that assessment for three reasons: the number of ED presentations was much higher than one would expect for a population with access to primary care services; there was a high number of repeat ED attendances by some individuals; and, compared with all patients, detainees had a low rate of admission after attendance at the ED.

As we analysed attendance using broad diagnostic categories, it is likely that we underestimated the extent of psychological morbidity. The most common non-psychiatric complaints (myalgias, headaches, non-specific abdominal pain and non-cardiac chest pain) are symptoms that are commonly due to somatisation in people with psychological distress.

The large number of ED attendances by immigration detainees also puts a substantial burden on the $\mathrm{RDH}$ ED. The 770 attendances by detainees during 2011 represented over 1\% of all ED attendances. Despite generally low acuity in terms of triage category, resource utilisation was high, with significant proportions of patients needing $\mathrm{x}$-rays, blood tests and refer- rals to inpatient teams. We did not collect data for 2012 or 2013, but we note that the number of RDH ED attendances by immigration detainees appears to have declined since 2011, probably due to increases in primary health care resources in immigration detention facilities in Darwin and a decrease in average length of stay (277 days in November $2011 \mathrm{v} 114$ days in February 2013). ${ }^{1}$ We hypothesise that this was also influenced by the Australian Human Rights Commission and Auditor-General reports ${ }^{6,7}$ and by public advocacy.

Our study has several limitations. The main limitation relates to the difficulty in obtaining clear and accurate data on the number of people in detention in Darwin during 2011. As a result, we estimated denominators by extrapolation of available data; hence we may have underestimated the number of immigration detainees in Darwin and thus overestimated the proportion who attended the ED. However, as the total capacity of the immigration detention facilities in Darwin during most of 2011 was about 900, we believe our estimated average population of 776 reflects the true situation in Darwin in 2011.

We interpreted the lower admission rates for detainees in each triage category to mean that primary health care services at the immigration detention facilities were deficient, because generally people are discharged from hospital when they have a condition that is of low acuity and severity and could be managed adequately in primary care. Alternatively, for nonmedical reasons, doctors might have had a higher threshold for admitting detainees to hospital (eg, detainees were being discharged to supervised accommodation). Irrespective of the explanation, the high numbers of ED attendances and repeat attendances support the assertion that primary care services for people living in immigration detention in Darwin in 2011 were deficient.

We collected our data retrospectively, mostly in categorical form, so our results lack detail about individual diagnoses and presentations. However, the data on diagnoses are likely to be accurate because they were coded and recorded prospectively by doctors as a routine part of ED practice. A prospective real-time study would provide more accurate data, and could include a qualitative component, but this would require time and funding that was beyond the scope of our study.

Our data show that there was a high prevalence of unmet health need, particularly relating to psychiatric morbidity, and limited access to primary health care services, for immigration detainees in Darwin in 2011.

Acknowledgements: We thank Antony Robinson for assisting with database development and Mark Loewenthal for assisting with statistical analyses. Joshua Davis' salary was funded by the National Health and Medical Research Council (Early Career Fellowship Number 1013411)

Competing interests: No relevant disclosures. Received 8 Apr 2013, accepted 13 Oct 2013.

1 Department of Immigration and Citizenship. Immigration Detention Statistics Summaries 2011. Canberra: Department of Immigration and Citizenship. http://pandora.nla.gov.au/tep/ 115165 (accessed Apr 2013).

2 Hallas P, Hansen AR, Staehr MA, et al. Length of stay in asylum centres and mental health in asylum seekers: a retrospective study from Denmark. BMC Public Health 2007; 7: 288.

3 Steel Z, Momartin S, Bateman C, et al. Psychiatric status of asylum seeker families held for a protracted period in a remote detention centre in Australia. Aust N Z J Public Health 2004; 28 : 527-536.

4 Bischoff A, Denhaerynck K, Schneider M, Battegay $E$. The cost of war and the cost of health care - an epidemiological study of asylum seekers. Swiss Med Wkly 2011; 141: w13252.

5 Correa-Velez I, Johnston V, Kirk J, Ferdinand A Community-based asylum seekers' use of primary health care services in Melbourne. Med $J$ Aust 2008; 188: 344-348.

6 Australian Human Rights Commission. Immigration detention in Darwin: summary of observations from visits to immigration detention facilities in Darwin. Sydney: Australian Human Rights Commission, 2010. http:// www.humanrights.gov.au/human_rights/ immigration/idc2010_darwin.html (accessed Apr 2013).

7 Auditor-General. Individual management services provided to people in immigration detention. Canberra: Australian National Audit Office, 2013. (Audit Report No. 21 2012-13 Performance Audit.) http://www.anao.gov.au/ Publications/Audit-Reports/2012-2013/ Individual-Management-Services-Provided-toPeople-in-Immigration-Detention (accessed Apr 2013).

8 Goosen S, Kunst AE, Stronks K, et al. Suicide death and hospital-treated suicidal behaviour in asylum seekers in the Netherlands: a national registry-based study. BMC Public Health 2011; 11 : 484.

9 Keller AS, Rosenfeld B, Trinh-Shevrin C, et al. Mental health of detained asylum seekers. Lancet 2003; 362: 1721-1723.

10 Ichikawa M, Nakahara S, Wakai S. Effect of postmigration detention on mental health among Afghan asylum seekers in Japan. Aust N Z J Psychiatry 2006; 40: 341-346. 